\title{
Reliability of recharge rates estimated from groundwater age with a simplified analytical approach
}

\author{
Yanhui Dong ${ }^{1}$, Yueqing Xie ${ }^{2}$, Jun Zhang ${ }^{3}$, Andy Love ${ }^{4}$, and Xin Dai ${ }^{5}$ \\ ${ }^{1}$ Institute of Geology and Geophysics Chinese Academy of Sciences \\ ${ }^{2}$ Nanjing University \\ ${ }^{3}$ Chinese Geological Survey \\ ${ }^{4}$ Flinders University \\ ${ }^{5}$ Nanjing University, Nanjing, China
}

November 18, 2020

\begin{abstract}
Groundwater age is often used to estimate groundwater recharge through a simplified analytical approach. This estimated recharge is thought to be representative of the mean recharge between the point of entry and the sampling point. However, given the complexity in actual recharge, whether the mean recharge is reasonable is still unclear. This study examined the validity of the method to estimate long-term average groundwater recharge and the possibility of obtaining reasonable spatial recharge pattern. We first validated our model in producing reasonable age distributions using a constant flux boundary condition. We then generated different flow fields and age patterns by using various spatially-varying flux boundary conditions with different magnitudes and wavelengths. Groundwater recharge was estimated and analyzed afterwards using the method at the spatial scale. We illustrated the main findings with a field example in the end. Our results suggest that we can estimate long-term average groundwater recharge with $10 \%$ error in many parts of an aquifer. The size of these areas decreases with the increase in both the amplitude and the wavelength. The chance of obtaining a reasonable groundwater recharge is higher if an age sample is collected from the middle of an aquifer and at downstream areas. Our study also indicates that the method can also be used to estimate local groundwater recharge if age samples are collected close to the water table. However, care must be taken to determine groundwater age regardless of conditions.
\end{abstract}

\section{Hosted file}

Varying_recharge_v7.pdf available at https://authorea.com/users/376809/articles/493685reliability-of-recharge-rates-estimated-from-groundwater-age-with-a-simplifiedanalytical-approach 